\title{
Perception of resyllabification in French
}

\author{
M. GARETH GASKELL \\ University of York, York, England \\ ELSA SPINELLI \\ Max Planck Institute for Psycholinguistics, Nijmegen, The Netherlands \\ and \\ FANNY MEUNIER \\ MRC Cognition and Brain Sciences Unit, Cambridge, England
}

\begin{abstract}
In three experiments, we examined the effects of phonological resyllabificationprocesses on the perception of French speech. Enchainment involves the resyllabification of a word-final consonant across a syllable boundary (e.g., in chaque avion, the / $/$ crosses the syllable boundary to become syllableinitial). Liaison involves a further process of realization of a latent consonant, alongside resyllabification (e.g., the /t/ in petit avion). If the syllable is a dominant unit of perception in French (Mehler, Dommergues, Frauenfelder, \& Segui, 1981), these processes should cause problems for recognition of the following word. A cross-modal priming experiment showed no cost attached to either type of resyllabification in terms of reduced activation of the following word. Furthermore, word- and sequencemonitoring experiments again showed no cost and suggested that the recognition of vowel-initial words may be facilitated when they are preceded by a word that had undergone resyllabification through enchainment or liaison. We examine the sources of information that could underpin facilitation and propose a refinement of the syllable's role in the perception of French speech.
\end{abstract}

Languages such as French, Spanish, and Portuguese have a clear, simple syllabic structure. Consequently, for the language learner and the adult native speaker of such a language, the syllable is an important perceptual unit. In a classic study, Mehler, Dommergues, Frauenfelder, and Segui (1981) demonstrated the importance of syllabic information, using a syllable-monitoring task. Native French speakers listened to pairs of words, such as balcon and balance. These bisyllabicitems differ in terms of the position of the syllable boundary with respect to the first three segments. In bal.con (syllable boundaries are marked with a full stop), the boundary occurs - as it would in an equivalent English word-between the /1/ and the /c/. However, in ba.lance the boundary occurs between the /a/ and the $/ 1 /$. This is different from the equivalent case in English, in which the /1/ is ambisyllabic. Mehler et al. showed that when participants were asked to monitor for syllable sequences such as $/ \mathrm{ba} /$ or $/ \mathrm{bal} /$, responses were faster when

Part of this research was carried out while the first two authors were at the MRC Cognition and Brain Sciences Unit, Cambridge. This article is based in part on a talk given at the XXVII International Congress of Psychology, Stockholm, Sweden, July 2000. We thank Juan Segui for advice and the use of his facilities in testing participants and members of the MRC Cognition and Brain Sciences Unit in Cambridge for valuable discussions on this research. Thanks are also due Sami Boudelaa, Nicolas Dumay, Uli Frauenfelder, David Gow, and an anonymous reviewer, who commented on an earlier version of this manuscript. Correspondence concerning this article should be addressed to M. G. Gaskell, Department of Psychology, University of York, York YO10 5DD, England (e-mail: g.gaskell@psych.york.ac.uk). the target matched the first syllable of the stimulus word entirely. That is, responses to the /ba/-balance and /bal/-balcon pairings were relatively fast, as compared with the /bal/- balance and /ba/-balcon pairings.

In subsequent research within and between a variety of languages, the generality of this effect has been examined. Studies of Spanish and Portuguese revealed similar stimulustarget interactions, whereas English, which has a less regular syllabic structure, failed to show the critical interaction (Bradley, Sánchez-Casas, \& García-Albea, 1993; Cutler, Mehler, Norris, \& Segui, 1986; Morais, Content, Cary, Mehler, \& Segui, 1989). However, the syllable effect in Spanish appears to rely on relatively slow responses (Sebastian-Gallès, Dupoux, Segui, \& Mehler, 1992), and syllable effects in Catalan occur only in certain circumstances (Sebastian-Gallès et al., 1992). The conclusion drawn from this body of research is that syllable regularity and transparency are both important determiners of the reliance of the perceptual system on the syllable. In stresstimed languages like English, the syllable in itself is not the most important unit. Instead, a strong syllable (a syllable containing a full vowel) is a more reliable cue to a word onset (Cutler \& Norris, 1988). For syllable-timed languages, the ease with which subsyllabic units can be identified is important, with a greater reliance on syllable units in a language with many vowels (e.g., French) and less reliance on syllables in a language with a smaller vowel inventory (e.g., Spanish). ${ }^{1}$

These perceptual procedures are grounded in the statistics of the language. Cutler and Carter (1987) showed that 
more than $90 \%$ of English content words begin with a strong syllable, and for the remaining items there is a cost attached, in that they are more likely to be misperceived (Cutler \& Butterfield, 1992).2 Likewise, other statistical strategies have gained favor as developmental and adult segmentation models, based on phonotactic and distributional properties of speech (e.g., Brent, 1999; Saffran, Aslin, \& Newport, 1996). What then is the cost of a syllablebased model of the perception of French? Just as, for English, it is more difficult to recognize content words with weak-strong metrical stress patterns (Cutler \& Butterfield, 1992), so in French, it may be difficult to recognize words whose onsets do not coincide with a syllable boundary. This can occur for a number of reasons, particularly for words beginning with vowels.

One reason for misalignment is that many French function words are reduced to single consonants when followed by a vowel (e.g., l'eau, t'appelle, n'aime). The words following these reduced forms are misaligned with syllable onset. Resyllabification, or enchainment, of word-final consonants creates the same state of affairs. For example, the final consonant of chaque would be syllable-final when followed by a consonant such as /t/ (e.g., chaque train [each train]) but would migrate to the onset of the following syllable when followed by a vowel (e.g., chaque avion [each aircraft]). Resyllabification can also occur in combination with liaison, in which a latent consonant migrates to syllable-onset position when followed by a vowel or, less frequently, a glide (e.g., the final /t/ in le petit avion [the little aircraft]). The consonant is termed latent because when the word is produced in isolation or is followed by a stop consonant or a fricative, the consonant is not realized (e.g., le petit chien [the little dog]).

These phenomena are complex, and their application depends on phonetic, syntactic, morphological, and stylistic factors. Nonetheless, the simple fact remains that there are several related processes that cause glide-initial and, particularly, vowel-initial words to be nonaligned with syllable onsets in connected speech. Our goal in this study was to examine the consequences of this misalignment on the recognition of such words.

Although there are differences between languages in terms of the importance of the syllable, there are also grounds for supposing that misalignment between syllable and word boundaries will cause problems for word recognition in all languages. The possible word constraint (PWC), developed by Norris, McQueen, Cutler, and Butterfield (1997), states that a potential segmentation of the speech stream is disfavored if it leaves a consonant or consonant sequence stranded between a known word boundary and a hypothesized boundary. This constraint was used to explain data from word-spotting experiments, in which participants were asked to press a button as soon as they detected any word in a short sequence of speech. Norris et al. argued that it is easier to spot the word sea in seashub than in seash because, although both segmentations involving sea leave a nonword residue, the residue in seashub is a possible word (shub), whereas the residue in seash $(s h)$ is not. The same pattern of results was found for offsetembedded words, such as apple embedded in vuffapple (possible word) and fapple (impossible word). Norris et al. also argued that a known word boundary can be generalized to include likely word boundaries, where a likely boundary is a syllable onset. Thus, any misalignment between a word onset and a likely word boundary defined in this way should have an associated cost, in terms of delayed recognition of the misaligned word. Cutler, Demuth, and McQueen (2002) argued, on the basis of studies in a variety of languages, that the PWC is a language-universal constraint irrespective of the size of legal word units. French is an interesting test case for the PWC, because single consonantscan, in fact, be possible words in French (e.g., the /1/in l'eau [the water]) and because of the prevalence of resyllabification. Norris et al. noted that this strategy would cause problems for resyllabification and, particularly, French liaison. Their suggested solution was that the PWC might be switched off when a liaison consonant was recognized. The present research tests whether this is the case.

Vroomen and de Gelder (1997) found evidence for a syllable-word boundary misalignment cost, although they did not interpret their effect in terms of the PWC. They used cross-modal priming to examine the activation of various types of embedded words in Dutch. When the embedded word matched a syllable onset (e.g., boos [angry] in framboos [raspberry]), the recognition of a word related to the embedded word was facilitated. This effect did not hold when a word was embedded in a longer syllable (e.g., wijn [wine] in zwijn [swine]). McQueen (1998) reported a comparable effect—also in Dutch—using word spotting. He found that a word such as rok (skirt) was easier to detect when embedded in fiem.rok (target aligned with syllable boundary) than when embedded in fie.drok (target misaligned with syllable boundary). A similar but weaker effect was found when the word offset was misaligned with the syllable boundary. In McQueen, these syllable boundaries were enforced by the phonotactic rules of the language, suggesting that syllabification effects may partly reflect the use of phonotactic knowledge in speech segmentation. For French, Dumay, Frauenfelder, and Content (2002) studied syllable-word alignment effects at both onset and offset, again using word spotting. Like McQueen, they found a processing cost involved in syllable misalignment, although in this case, it was significant only when the onset of the word mismatched the syllable boundary (e.g., lac [lake] embedded in zun.lac vs. zu.glac).

These studies suggest that words that are misaligned with syllable boundaries are relatively difficult to recognize, in both syllable-timed and stress-timed languages. However, none of the studies mentioned so far tested a situation in which misalignment was embedded in normal sentence context, which is relatively common in French through resyllabification and reduction processes. Vroomen and de Gelder (1999) addressed the issue of sentenceembedded resyllabification for Dutch by asking partici- 
pants to monitor for phonemes, such as the / $\mathrm{t} /$ in boot (boat). The phonemes either occurred in their normal syllablefinal position (e.g., de boot, die gezonken is [the boat, which is sunk]) or were resyllabified owing to the presence of a following vowel (e.g., de boot is gezonken [the boat is sunk]). Once again, the misalignment of word and syllable boundaries resulted in slower performance in the resyllabification condition.

Therefore, at least in Dutch, there is a resyllabification cost in terms of identifying the resyllabified consonant itself. If the syllable is a more influential perceptual unit in French than in languages like English and Dutch (Mehler et al., 1981), resyllabification costs may be even more drastic in French. However, Vroomen and de Gelder (1999) examined the effects of resyllabification on the recognition of the resyllabified consonant itself. Although resyllabification may induce uncertainty about the status of that particular consonant, identification of the resyllabified consonant may have predictive value for the recognition of the following word. The situation is similar in cases of assimilation of place of articulation, in which the assimilated consonant becomes somewhat ambiguous (e.g., Gaskell \& Marslen-Wilson, 1998) but identification of the assimilated consonant narrows down the possibilities for the next segment, because that next segment must be one that will allow the assimilation process to occur in the first place. Furthermore, there is some evidence that resyllabified consonants differ from normal syllable-initial consonants (Dumay, Content, \& Frauenfelder, 1999; Spinelli, McQueen, \& Cutler, in press). If this is the case (the evidence currently available for French is by no means compelling), it may be better to think of resyllabification owing to liaison and enchainment as a partial or graded process. A graded resyllabification process would cause nonalignment between word and syllable boundaries but would leave some acoustic markings that could be used to counter the negative effects of word boundary misalignment or, possibly, even facilitate processing. Again, there is a strong parallel with English place assimilation, which can be complete or partial. For cases of partial assimilation, the perception of the assimilated segment can facilitate recognition of the following context that licenses the change (Gow, 2001; Quené, van Rossum, \& van Wijck, 1998).

In the case of liaison, resyllabification applies to a latent consonant, which may further complicate the process of constructing the appropriate segmentation of the speech. It is safe to assume that words for which the final consonant is often not pronounced will be recognizable without that consonant. Therefore, there is the potential for increased lexical competition when the liaison consonant is encountered. For example, in the sequence excellent acteur (/عk.se.lã.tak.t $\mathrm{r} /$; excellent actor), a missegmentation may be briefly entertained in which the /t/ is treated as word initial, as in the phrase excellent tableau (/عk.se.lã.ta.blo/; excellent painting).In phonemic terms, these sequences are identical until the end of the /a/, and given that the incorrect segmentation is favored by alignment with the syllable onset, the competition effects of /ta/-initial words may take some time to diminish. These ambiguities were studied by Dejean de la Bâtie and Bradley (1995), who asked participants to monitor for a wordinitial / $t$ / in phrases like the ones above. A participant performing correctly on this task would respond when excellent tableau (potentialliaison) was presented, but not when excellent acteur (actual liaison) was presented. Native French speakers made very few errors in this task, but there was some evidence that potential liaisons delayed responses. Responses were slower to potential liaison sequences than they were to unambiguous sequences (e.g., vrai tableau [real painting]). This difference was significant $(64 \mathrm{msec})$ when the sentence contexts were fairly short and neutral, but it was not significant $(24 \mathrm{msec})$ when the sentence contexts were fuller and more informative. Therefore, there is an added reason to suspect that liaison sequences may affect the recognition of the following segment. On top of the fact that liaison causes misalignment between syllable and word boundaries, it could also increase the number of lexical hypotheses that must be considered, which would further delay the activation of the following word. However, it is important to bear in mind that the situation we focus on here differs in an important way from the situation examined by Dejean de la Bâtie and Bradley. Their experiment primarily examined the effects of potential liaison on the identification of a wordinitial consonant (e.g., excellent tableau), whereas here we study the effect of actual liaison on the recognition of the following vowel-initial word.

There are, therefore, several theoretical reasons for predicting that liaison and enchainment will affect speech perception. We report three experiments in which the effects of these processes on the recognition of vowel-initial words were examined. In one condition, the critical vowel-initial word began at a syllable boundary. In two other conditions, the critical word onset was misaligned with a syllable boundary, because either enchainment or liaison caused the final consonant of the preceding word to resyllabify. In Experiment 1, we used these phrases as prime sentences in a cross-modal priming experiment designed to examine the lexical activation of the vowel-initial word at two different points during the perception of that word (roughly halfway through the word and at the offset of the word). In Experiment 2, we looked at the ease of identification of the onset of the word, using a word-monitoring task. Finally, in Experiment 3, we addressed the critical acousticphonetic information in these sequences. The ease of recognition of the critical word-initial segments on the basis of acoustic-phonetic information alone (i.e., when normal lexical competition was unavailable) was assessed by asking participants to monitor for short sequences of segments in longer nonword sequences excised from the original phrases.

\section{EXPERIMENT 1}

In Experiment 1, cross-modal priming was used to assess the effects of resyllabification processes on the activation 
of the following word. In Experiment 1A, a typical trial involved the presentation of an auditory prime sentence to the participant, with the visual form of the final word displayed at the offset of the sentence. The speed of response to the visual target gave an indication of the degree to which the lexical representation of that word had been activated. In Experiment 1B, the procedure was repeated with the target presented earlier in the sentence- $50 \mathrm{msec}$ before the isolation point of the critical word-in order to assess activation earlier in the recognition process.

\section{Method}

Participants. Eighty-four paid native French speakers of the same dialect took part in this experiment (40 in Experiment 1A and 44 in Experiment 1B). The participants either were students at the Université René Descartes in Paris or were recruited in Cambridge through the university and language schools.

Materials and Design. Thirty vowel-initial words with masculine gender, selected from the Trésor de la Langue Française (Imbs, 1971), served as the experimental targets. These were embedded in three types of phrasal context to form three related prime conditions (see Table 1 for examples and the Appendix for the full stimulus list). In the liaison condition, the prime phrase consisted of the article un followed by a word containing a latent final consonant (e.g., généreux), followed by the target word (e.g., italien). The vowel beginning the target word ensured that the latent consonant (e.g., the /z/ in généreux) was both fully realized and resyllabified to become syllable initial. In the enchainment condition, resyllabif ication occurred but involved a consonant that was fully realized in all phonological contexts (e.g., the /z/ in virtuose). With one exception, the liaison and enchainment conditions were matched, within each item set, on the identity of the resyllabified consonant $(/ \mathrm{t} /, / \mathrm{z} /$ or $/ \mathrm{r} /)$. In the syllable-aligned condition, the onset of the target word coincided with a syllable boundary. This was achieved by choosing a preceding word that ended in a vowel (e.g., chapeau). The three related prime conditions were compared with a control condition in which the same visual target word was paired with an unrelated prime phrase in order to provide a baseline for measuring response facilitation (e.g., for the target word italien, the control prime phrase was un mysterieux organisme). The control prime began with a vowel and was embedded in either a liaison or an enchainment sequence (there were equal numbers of each type of control, and this contrast had no effect on the results). The average frequency of the targets (which were also the prime words in three of the four conditions) was 100 occurrences per million (median, 22). The control prime words had a mean frequency of 52 (median, 23).

The preceding contexts of the related prime word (see Table 1 for frequencies and durations of these words) were designed to make the final word equally plausible and equally predictable in all three conditions. Predictability was measured with a cloze test, in which the first two words of the stimulus phrases were given in written form to 16 native French-speaking participants, who were asked to provide plausible one-word continuations. The test showed that final words were generally unpredictable, with only 35 out of 1,920 continuations $(1.8 \%)$ matching the target word and no significant differences between conditions. Of the matching continuations, 29 were attributable to just three stimuli with high cloze ratings (un galant homme [a gallant man], un honnete homme [an honest man], and un hereux evenement [a fortunate event]). Thus, almost all the continuations in the spoken stimuli were unpredictable. Given that cloze predictabilities were low (and so, floor effects could possibly be masking a systematic plausibility bias), a two-alternative preference test was also used to test for possible biases in the context sentences. Forty native French speakers rated the relative plausibility of either the liaison versus the enchainment primes or the liaison versus the syllable-aligned primes ( 20 participants in each test). In both cases, the two versions of the prime phrase were presented to the participant in written form with instructions to rate their relative plausibility on a 9-point scale (extremes of the scale represented a preference for one or other of each pair, and the middle of the scale represented no preference). The advantage of this method was that it allowed the different contexts of each critical word to be compared directly. The pretest produced a satisfactory spread of scores, but overall there was no systematic semantic bias toward any one of the conditions. The mean preference scores were 4.9 for liaison versus enchainment and 4.8 for liaison versus syllable aligned. Neither value deviated significantly from the no-preference baseline of 5. The results of the two pretests confirmed that there were no differences between the spoken stimuli in terms of contextual plausibility or predictability of the final words. There was, however, one unavoidable difference between the different context types. The liaison condition exclusively used article-adjective-noun phrases, whereas the enchainment condition mostly used the more common article-noun-adjective structure ( 21 out of 30 items). This difference was due to the relative scarcity of nouns that undergo liaison and meant that some targets were used as adjectives in one condition and as nouns in another. The syllable-aligned condition was matched in phrase structure with the enchainment condition. These syntactic differences did not lead to any differences in the predictability of the final word, but they need to be borne in mind when the results are interpreted.

A set of 120 filler items was constructed in a similar manner to the test set. Of the fillers, 45 used visual targets that were words and were unrelated to the prime phrase. Thirty of these contained words that would be resyllabified if followed by a vowel (15 liaison words, 15 enchainment) but were followed by a consonant (e.g., un audacieux montagnard, where the /z/ in audacieux remained unarticulated because of the following stop consonant). These potential resyllabification sentences ensured that resyllabification was not predictable in the stimulus set as a whole. A further 15 fillers with word targets, like the syllable-aligned primes, used a penultimate word ending in a vowel but differed in that the final word began with a consonant. The remaining 75 filler items used nonword visual targets, meaning that $50 \%$ of the targets in the experiments were words. The prime phrases for these targets were similar to the primes for the word targets: Thirty contained liaisons or potential liaisons, 30 contained enchainments or potential enchainments, and 15 contained a vowel-final word followed by a consonant. To ensure that a form link between prime and target was not predictive of a word target, 22 of

Table 1

Example Stimuli for Experiment 1

\begin{tabular}{llccc}
\hline \multicolumn{1}{c}{ Condition } & \multicolumn{1}{c}{ Spoken Prime Phrase } & Visual Target & $\begin{array}{c}\text { Context Word } \\
\text { Length }(\mathrm{msec})\end{array}$ & $\begin{array}{c}\text { Context Word Frequency } \\
\text { (mean/median) }\end{array}$ \\
\hline Liaison & un généreux italien & italien & 380 & $230 / 58$ \\
Enchainment & un virtuose italien & italien & 447 & $184 / 31$ \\
Syllable aligned & un chapeau italien & italien & 391 & $86 / 56$ \\
Control & un mysterieux organisme & italien & 411 & $91 / 54$ \\
\hline
\end{tabular}


the nonword targets were superficially similar to the final word of the prime phrase (e.g., un navire immerge-IMMERSU). The percentage of trials in which there was a link between prime and target was $29 \%$.

The stimulus phrases were recorded onto DAT by a native French speaker (the second author) and were transferred digitally to computer disk. In Experiment 1A, the alignment point for the presentation of the visual target was the offset of the prime word (at the end of the prime phrase), in order to assess lexical activation near the end of the recognition process. In Experiment 1B, the target was placed at a point at which lexical competition was expected to be in progress. This point was selected on the basis of a separate gating task (Grosjean, 1996) involving new recordings of the related prime words in isolation. These recordings were presented in gradually increasing fragment duration to 11 native French speakers who did not take part in the main experiment. The shortest fragment consisted of the first $150 \mathrm{msec}$ of the word, and the fragments increased in length by $50 \mathrm{msec}$ each time until the full word was presented. For each fragment, the participant had to attempt to identify the word and rate the confidence of his or her judgment on a 9-point scale. For each participant and each word, the gate position at which the correct answer was first given and after which the participant did not change his or her mind was identified, and the isolation point of each word was calculated by taking the average of these gate positions across participants. The mean duration of the isolated words was $643 \mathrm{msec}$, and the mean isolation point was $348 \mathrm{msec}$. The target position for Experiment 1B was chosen to be $50 \mathrm{msec}$ before the isolation point for the critical word (on average, $298 \mathrm{msec}$ into the word). In order to map these target points derived from isolated gated words onto the same words in sentence context, the target point was transformed into a percentage duration of the word, and these percentages were mapped onto the words in context. Thus, if the isolation point less $50 \mathrm{msec}$ turned out to be $40 \%$ of the way through a word, the alignment point for target onset in Experiment $1 \mathrm{~B}$ was placed $40 \%$ of the way through that word in each of the three prime conditions containing that word. This controlled in a simple way for the small variations in duration between the tokens of the target word in these conditions (the overall durations of the prime words in the three conditions were similar to the durations of the isolated words; mean prime word durations were 635,627 , and $643 \mathrm{msec}$ for the liaison, enchainment, and syllable-aligned conditions). The target alignment points were mapped onto the final word of the control prime phrases, using the same percentages.

Four experimental lists were created, each containing one of the four stimulus phrases for each experimental item. This ensured that any 1 participant would hear only one version of each test item. Experimental items were pseudorandomly ordered, and the lists began with 10 practice trials.

Procedure. The participants were tested individually in a quiet room. Each prime was presented auditorily at a comfortable sound level through Sony CD550 headphones. At the end of the auditory prime (Experiment 1A) or during the course of the final word of the prime (Experiment $1 \mathrm{~B}$ ), the target was visually displayed in lowercase at the center of a computer screen for $480 \mathrm{msec}$. The prime phrase was not cut off in either subexperiment. The participants had been informed that the visual target could be either a word or a pseudoword and had to perform a lexical decision task on the visual target by pressing one of two response buttons as accurately and as quickly as possible. They were required to press the yes button with the forefinger of their preferred hands. The reaction times were measured from the presentation of the visual target on the screen. Stimulus presentation was computer controlled using the DMDX experiment generator software developed by K. Forster and J. Forster at the University of Arizona. The duration of the session was approximately $20 \mathrm{~min}$.

\section{Results}

Participant and item analyses of variance (ANOVAs) were performed on the data, using the variable prime type (four levels). A dummy variable represented either the par-
Table 2

Results of Experiment 1 (Cross-Modal Priming)

\begin{tabular}{lccccccc}
\hline & \multicolumn{3}{c}{ Experiment 1A } & & \multicolumn{3}{c}{ Experiment 1B } \\
\cline { 2 - 4 } \cline { 6 - 8 } Condition & RT & Diff & ER & & RT & Diff & ER \\
\hline Liaison & 540 & 51 & 3.0 & & 583 & 41 & 0.7 \\
Enchainment & 533 & 59 & 3.4 & & 579 & 45 & 1.5 \\
Syllable aligned & 526 & 65 & 1.6 & & 582 & 42 & 2.0 \\
Control & 591 & & 6.7 & 624 & & 1.9 \\
\hline
\end{tabular}

Note-RT, reaction time in milliseconds; Diff, control-test difference (facilitation effect); ER, error rate as a percentage.

ticipant grouping in the allocation of participants to experimental lists (for the participants analyses) or the test item grouping in the allocation of items to lists (for the items analyses). Because it was included solely to reduce the estimate of random variation, effects involving the dummy variable are not reported (Pollatsek \& Well, 1995). Raaijmakers, Schrijnemakers, and Gremmen (1999) recommended that for experimental designs like ours involving matched sets of items, a significant by-participant effect is sufficient to reject the null hypothesis. We note this recommendation here but report both by-participant $\left(F_{1}\right)$ and by-item $\left(F_{2}\right)$ values for the sake of completeness.

The results of Experiment 1 are summarized in Table 2. For Experiment 1A, the ANOVA revealed a significant effect of prime type $\left[F_{1}(3,108)=15.9, p<.001 ; F_{2}(3,78)=\right.$ $24.5, p<.001]$. Planned comparisons showed that there were significant facilitative effects for the liaison $\left[F_{1}(1,36)=14.5, p<.01 ; F_{2}(1,26)=30.7, p<.001\right]$, enchainment $\left[F_{1}(1,36)=27.3, p<.001 ; F_{2}(1,26)=62.0\right.$, $p<.001]$, and syllable-aligned $\left[F_{1}(1,36)=40.7, p<\right.$ $\left..001 ; F_{2}(1,26)=120.4, p<.001\right]$ conditions. However, there were no differences between these conditions in terms of the amount of facilitation. An error analysis showed a similar effect of prime type $\left[F_{1}(3,108)=4.2\right.$, $\left.p<.01 ; F_{2}(3,78)=4.1, p<.05\right]$, with fewer errors in the primed conditions than in the control condition.

Experiment 1B, in which the target was placed earlier to assess activation during the competition, showed the same overall pattern of results. There was a strong effect of overall prime type $\left[F_{1}(3,120)=12.4, p<.001\right.$; $\left.F_{2}(3,78)=8.4, p<.001\right]$. Priming levels were about one third lower than the priming levels in Experiment 1A, but once again, there were individually significant facilitation effects for the liaison $\left[F_{1}(1,40)=18.1, p<.001\right.$; $\left.F_{2}(1,26)=14.0, p<.01\right]$, enchainment $\left[F_{1}(1,40)=30.0\right.$, $\left.p<.001 ; F_{2}(1,26)=13.4, p<.01\right]$, and syllable-aligned $\left[F_{1}(1,40)=26.1, p<.001 ; F_{2}(1,26)=13.3, p<.01\right]$ conditions. These numerically weaker effects suggest that the target word had not been fully activated by the time the target was presented, but nonetheless, there was no effect of the type of related prime on the amount of facilitation ( $F_{1}$ and $F_{2}<1$ in each case). There were no significant effects in the error analysis.

\section{Discussion}

In Experiment 1, we examined the effects of two types of resyllabification on the perception of following vowel- 
initial words in French. We anticipated that resyllabification might result in delayed or weakened activation of the following word, because of the resulting misalignment of word and syllable boundary. However, the cross-modal priming results in both subexperiments showed no hint of an effect. Certainly, if resyllabification does impede the recognition of the following word, the effect is swiftly offset by the segmental information in the speech stream. Experiment 1B demonstrated this most clearly; with the target presented less than $300 \mathrm{msec}$ into the spoken word, there was no difference in the amount of priming found in the three related conditions, suggesting that lexical activations were equivalent. This result does not sit easily with the proposition that the syllable is the critical unit of perception in French.

Although this result is perhaps surprising, given the theoretical and experimental background described in the introduction, it is not particularly strong scientifically; all three test conditions showed significant facilitation, but there was no significant difference between the three related conditions. It is possible that even in Experiment 1B, our target position was too late to catch the interference created by resyllabification. We could test this by shifting the target alignment point to earlier in the prime sentence so as to examine activations at an even earlier point, but this would run the risk of weakening priming in all conditions to a nonsignificant level. Priming dropped from around 60 to $40 \mathrm{msec}$ between Experiment $1 \mathrm{~A}$ and Experiment 1B, presumably because in Experiment 1B, lexical competition in response to the prime had not been fully resolved by the time the target was presented. Moving the target even earlier would most likely reduce the baseline priming levels even further, minimizing the chances of finding a difference in priming between conditions. Instead, in Experiment 2, the immediate effects of resyllabification and liaison were addressed with a different task — word monitoring (Kilborn \& Moss, 1996). This task offered the prospect of fast responses to the listener's evaluation of, primarily, the beginning of a spoken word ( particularly when no catch trials were used), and so if there was an early or transient effect of resyllabification, there would be a good chance that word monitoring would pick it up.

\section{EXPERIMENT 2}

In this experiment, trials began with the visual presentation of the target word (e.g., italien), and the participants were then asked to monitor for the target in the spoken phrase (e.g., un généreux italien).

\section{Method}

Participants. Thirty-nine paid native speakers of French took part in this experiment. The participants were recruited in Cambridge through the university and language schools, and none had participated in Experiment 1.

Stimuli and Design. The test stimuli consisted of the 30 sets of related prime sentences used in Experiment 1 (i.e., the liaison, enchainment, and syllable-aligned conditions). These were inter- spersed with 90 filler phrases selected from Experiment 1. For 30 of these, the chosen target word was the third and final word of the phrase, whereas for the remaining 60 , the chosen target was not in the phrase. This meant that $50 \%$ of the trials contained the target word. In all, $50 \%$ of the targets used in this experiment were vowel initial, with equal proportions of vowel-initial targets in targetpresent trials and target-absent trials. Some word-monitoring experiments have used target-absent trials in which there was a strong form similarity between the target and one word from the stimulus phrase. This encouraged listeners to wait until recognition was more or less complete before they responded. Here, however, we wanted to investigate processing early on in recognition, and so we specifically avoided this type of foil trial.

Three experimental lists were created, each containing one of the three stimulus phrases for each experimental item. This ensured that any one participant would hear only one version of each test item. Experimental items were pseudorandomly ordered, and each participant had 10 trials for each condition. The lists began with 10 practice trials.

Procedure. The participants were tested in small groups in a quiet room. They were asked to detect a word in a phrase, with the target word varying from trial to trial. The target was visually displayed in lowercase at the center of a computer screen for $750 \mathrm{msec}$, and then the screen went blank. The spoken phrase was presented auditorily at a comfortable sound level through headphones. The participants were instructed to press a response button as soon as they heard the target word or to do nothing if the target was not present. Response latencies were recorded from the marker point at the onset of the target word.

\section{Results}

ANOVAs were conducted on the response time and error data (see Table 3), with target context(liaison, enchainment, and syllable aligned) entered as a variable. There was a highly significant main effect $\left[F_{1}(2,72)=8.0, p<.01\right.$; $\left.F_{2}(2,54)=3.4, p<.05\right]$, showing that the context of the target word affected speed of response. This effect was investigated further with planned comparisons. Responses in the liaison and enchainment conditions were significantly faster than those in the syllable-aligned condition [liaison vs. syllable aligned, $F_{1}(1,36)=13.3, p<.01$, and $F_{2}(1,27)=6.0, p<.05$; enchainment vs. syllable aligned, $F_{1}(1,36)=8.7, p<.01$, and $\left.F_{2}(1,27)=4.6, p<.05\right]$. The enchainment and liaison conditions did not differ in terms of response speed $\left(F_{1}<1 ; F_{2}<1\right)$. The error analysis showed no effects of target context $\left(F_{1}<1 ; F_{2}<1\right)$.

Because of the many constraints operating on stimulus selection, we were unable to choose items that were perfectly matched on the frequency of the word preceding the target word. The mean frequencies of these words were 230,184 , and 86 for the liaison, enchainment, and syllablealigned conditions, respectively. These differences were due partly to the presence of a few high-frequency words, and in terms of median frequency, the conditions were better matched (median values: 58, 31, and 56 for the liaison,

Table 3

Results of Experiment 2 (Word Monitoring)

\begin{tabular}{lccc}
\hline \multicolumn{1}{c}{ Measure } & Liaison & Enchainment & Syllable Aligned \\
\hline RT $(\mathrm{msec})$ & 438 & 446 & 482 \\
Error rate $(\%)$ & 0.8 & 1.3 & 1.0 \\
\hline
\end{tabular}


enchainment, and syllable-aligned conditions, respectively). In order to check whether the frequency of the preceding word had any effect on response speed (cf. Foss, 1969), we examined the by-item correlation between preceding word frequency and mean response time. This showed no significant correlations either within conditions or with all three conditions pooled.

A similar analysis in which duration of the preceding word was used showed a significant negative correlation with response time when data were pooled for the three conditions $(r=-.219, p<.05)$, although the effects within each condition did not reach significance. This effect showed that response times tended to be shorter when the word preceding the target was long. Given that word offsets will be, on the whole, more identifiable for longer words, this result may suggest that lexical information about where a word is likely to end can facilitate recognition of the following word. Nonetheless, the effect of target word context cannot be explained by durational differences in the preceding word, because the main effect in the response time analysis remained significant $\left[F_{2}(2,53)=\right.$ $3.3, p<.05$ ] even when the duration of the preceding word was included as a covariate in the items analysis.

\section{Discussion}

Experiment 2 was intended to examine the effects of misalignment between syllable and word onsets early on in the processing of vowel-initial words. The speed of responses in this experiment (mean response times were between 400 and $500 \mathrm{msec}$ from word onset) suggests that this goal was achieved. By comparison, the priming experiments with the earlier target onset (Experiment 1B) elicited response times of between 850 and $950 \mathrm{msec}$ from the word onset (or between 550 and $650 \mathrm{msec}$ from target onset). The absence of catch trials with stimuli closely related but not identical to the target word enabled the participants to respond on the basis of partially matching onset information. In these circumstances, we found strong effects of the preceding context of vowel-initial words on their recognition. Contrary to our expectations, targets preceded by liaison or enchainment consonants were recognized more quickly than targets aligned with syllable boundaries. Instead of liaison and enchainment impeding the recognition of the following word, it seems that these processes actually facilitated the recognition of vowel-initial words. Clearly, these results do not conform to a segmentation strategy for French that places great emphasis on straightforward alignment between word and syllable onsets, since the only onset-aligned stimuli were the ones responded to the most slowly. How then can these findings be explained?

The liaison condition used an article-adjective-noun syntactic structure, whereas the other two conditions predominantly used an article-noun-adjective structure. It is possible that the article-adjective-noun structure is associated with facilitated processing of the final word in some way (although our pretests showed that there was no difference in terms of semantic plausibility or predictability of the final word). This could explain the advantage of the liaison condition over the syllable-aligned condition but would then leave unexplained the advantage of the enchainment condition over the syllable-aligned condition and the lack of an advantage of liaison over enchainment. Syntactic differences between the conditions were, therefore, unable to fully determine the pattern of recognition speed found but may have contributed to the response time advantage in the liaison condition alone.

A second potential explanation of the facilitatory effects found in Experiment 2 relies on successful recognition of the word containing the resyllabified consonant prior to encountering the resyllabification itself. If this is the case, the recognition system may be able to use the lexical information about the form of the recognized word to identify the final consonant as being resyllabified and word final, rather than simply word initial. For example, consider the case in which a participant hears a phrase containing enchainment (e.g., un virtuose italien). In many cases, the word preceding the target will be recognizable before the final consonant. If the final consonant is then recognized as syllable initial, the segment following it must be one that licenses resyllabification (i.e., a vowel or one of a limited set of consonants). Therefore, provided the word preceding the target can be recognized before offset, the resyllabified consonant can be used as a cue to the upcoming licensing context, which may facilitate recognition. The perceptual system has shown a similar sensitivity to phonological context in the case of alternations that were due to place assimilation (Gaskell \& MarslenWilson, 1998; Gow, 2001).

It is important to note, however, that this mechanism for facilitation is more viable for enchainment sequences than for liaison sequences, because the presence of the final consonant is obligatory in enchainment, but not in liaison. This means that the occurrence of a liaison consonant does not necessarily mark the end of a word. Instead, it could be the beginning of a new word that coincidentally matches the liaison consonant (cf. excellent acteur vs. excellent tableau; Dejean de la Bâtie \& Bradley, 1995). Therefore, on the basis of lexically governed phonological constraints, the target should be less predictable in the liaison condition than in the enchainment condition.

An alternative or supplementary interpretation relies more on acoustic markings of resyllabification. Although French is often cited as a language in which resyllabifications are clear, there is some evidence that a resyllabified consonant in French is not acoustically identical to a wordinitial consonant. Yersin-Besson and Grosjean (1996) looked at the perception of word sequences such as son oeuf (his egg), which, because of the liaison process, could be mistaken for an alternative word sequence (e.g., son neuf [his nine]). With a forced-choice recognition test, they found that listeners did find these phrases lexically ambiguous, with only a small preference for the "correct" disambiguation over the nonliaison alternative. YersinBesson and Grosjean also examined liaison sequences phonetically and found that liaison consonants were, on average, $10 \%$ shorter in duration than nonliaison consonants 
(although this difference was based on only eight item pairs and was not tested for significance).

More recent evidence suggests that the completeness of resyllabification involved in enchainment may vary depending on the consonants involved. Dumay et al. (1999) showed that there were significant acoustic differences between obstruent-liquid clusters (e.g., /tr/) involved in resyllabification (e.g., tante roublarde [wily aunt]) and the same consonants word initially (e.g., troublant [perturbing]). This was not the case for resyllabified /s/-obstruent pairs, which appeared to be identical to the equivalent word-initial sequences. These acoustic factors correlated with performance in a word-spotting task, suggesting that listeners can make use of resyllabification information in word boundary information. Furthermore, Spinelli et al. (in press) have demonstrated a shortening of the liaison consonant (15\%), as compared with similar nonliaison sequences. Consonants in enchainment sequences had an intermediate duration.

Similar analyses were conducted post hoc on the stimuli from our experiments. For the liaison and enchainment stimulus sets, the durations of the resyllabified consonants were measured by analysis of the waveforms and spectrograms. The consonants were measured from the end of the second and third formants of the preceding vowel until the beginning of the second and third formants of the following vowel. These items were matched (for 29 of the 30 sets) on the resyllabified consonants $(14 / \mathrm{t} /, 7 / \mathrm{r} /$, and $8 / \mathrm{z} /)$, but not on the preceding segment. The consonants had a mean duration of $73 \mathrm{msec}$ in the liaison condition and $74 \mathrm{msec}$ in the enchainment condition (no significant difference). These values are similar to the values extracted from the Spinelli et al. (in press) stimuli (70 and $75 \mathrm{msec}$ ), for which the same speaker was used. Our experiment had no matched test stimuli in which the critical consonants were word initial, so we selected all items from the filler materials that contained a /t/, /r/, or /z/ in a word-initial position (19 items: $11 / \mathrm{t} /, 3 / \mathrm{r} /$, and $5 / \mathrm{z} /$ ). Despite this set's having a smaller proportion of the phoneme with the longest duration $(/ \mathrm{t} /)$, it still had a mean duration of $88 \mathrm{msec}$, which was similar to the comparable condition in Spinelli et al. $(82 \mathrm{msec})$ and was significantly higher than the means for the two sets of resyllabified consonants [for both analyses, $t(47)=2.2$, $p<.05]$. These post hoc analyses, therefore, agreed with other studies showing a reduction in consonant duration for cases of liaison and enchainment. It is plausible that these cues are combined with lexical information to improve the prediction of the following segment. Moreover, if these acoustic differences are particularly salient, they may provide a cue to the upcoming vowel even in the absence of lexical knowledge about the previous word.

A fourth possibility with an even stronger focus on the acoustic information in the signal is that the conditions vary simply in terms of the intelligibility of the speech. For example, it is possible that transitions between adjacent vowels make the second vowel difficult to identify, in which case the effects shown in Experiment 2 would have to be reevaluated.
To summarize, there are four potential sources of information that, in some combination, may provide the means for the facilitation effects shown in Experiment 2. Syntactic differences between the auditory stimuli may contribute to the advantage for the liaison condition. Lexical knowledge about the offset of the preceding word, combined with sensitivity to phonological constraints, may facilitate processing, particularly in the enchainment condition. Acoustic markings of resyllabification may facilitate processing in both liaison and enchainment conditions. Finally, there may be differences between consonant-vowel and vowelvowel transitions that inhibit recognition of the second vowel in the syllable-aligned condition. To test these alternative explanations, we would need a task in which the identification of the same word-initial information in the target words was examined, but in a case in which recognition of the relevant words would fail, denying access to high-level information. Vroomen and de Gelder (1999) were faced with a similar issue in their study of resyllabification effects in Dutch. Their response was to embed the critical segments in nonsense words, prohibiting lexical involvement in their task (phoneme monitoring). This manipulation eliminated the disadvantagefound for the resyllabified stimuli, confirming the lexical involvement in the original result. Similarly, Frauenfelder and Content (1999) demonstrated that the Mehler et al. (1981) syllabification effect in French (e.g., ba.lance vs. bal.con) was eliminated when the target syllables were embedded in nonwords (e.g., pa.loune vs. pal.nuffe). Frauenfelder and Content argued that in the absence of a match between speech input and word representations, the way in which speech is syllabified becomes unimportant. Instead, the task becomes one of simply finding a phonemic match to the target sequence.

Experiment 3 applies this "delexicalization" methodology to the present study. To ensure that the precise acoustic properties of the critical segments were preserved, excised sections of the original recordings from the first two experiments were used. The beginnings and ends of each recorded phrase were removed, making the original words difficult to recognize. For example, the ends of un virtuose italien were cut out, leaving tuose ita. This manipulation may not completely eliminate a lexical strategy, but it will certainly reduce its influence. To further discourage lexical processing, the task of the participant was altered from word monitoring to phoneme sequence monitoring. The target fragment in each case was the initial vowel of the target, plus the following consonant (e.g., instead of italien, the participant would monitor simply for $i t$ ). This task was preferred over monitoring for the vowel alone, because it reduced task difficulty.

\section{EXPERIMENT 3}

\section{Method}

Participants. Forty-five paid native speakers of French took part in this experiment. The participants were recruited in Cambridge through the university and language schools, and none had participated in either of the first two experiments. 
Table 4

Results of Experiment 3 (Fragment Monitoring)

\begin{tabular}{lccc}
\hline \multicolumn{1}{c}{ Measure } & Liaison & Enchainment & Syllable Aligned \\
\hline RT $(\mathrm{msec})$ & 730 & 787 & 778 \\
Error rate $(\%)$ & 7.1 & 9.6 & 12.5 \\
\hline
\end{tabular}

Stimuli and Design. The recordings from Experiment 2 were used, but with the beginnings and ends cut off to make the use of lexical information more difficult. The article (un) was removed, and a syllable was cut from either end, ensuring that the second word in the phrase was affected, plus the target from the word-monitoring experiment. There was always at least a syllable of the target word remaining, and often more. The targets for the test sentences were the initial vowel and consonant of the earlier target word (e.g., $o b$ from objectif ). In some cases, the target was contained within a single syllable, and in others, the target included the initial consonant of the next syllable (e.g., am in amateur). In one case (ex in exemplaire), the target contained two consonants. Given the null effect found in Frauenfelder and Content (1999), these syllabification differences were assumed to be unimportant. In all, there were 30 test items and 90 fillers, plus 10 practice items. The fillers were constructed and excised in the same way as the test sentences, and each target item was paired with 3 filler items employing the same target, 1 of which actually contained the target. In this way, $50 \%$ of the target items were present in the sentences ( 30 test +30 fillers). The target sequences were recorded using a different native French speaker. As before, three experimental lists were used in order to counterbalance conditions and avoid repetition of targets.

Procedure. The participants were first familiarized with the auditory targets by presenting them one by one, accompanied by a written list of three words that contained those sequences (e.g., for the target $i$, the familiarization words were item, agiter, and marmite). The words in the list exemplified the range of spellings that corresponded to the phonological target, contained the target at different points in the word, and used different syllabifications. Each target sequence was presented twice, with participants controlling the pace of the familiarization.

The detection task followed. The participants were asked to detect the target sequence in the shortened phrase. The target was presented through headphones, followed by a 1,500-msec gap and a visual cue (a cross on the screen). Next, the phrase fragment was presented auditorily. The participants performed the monitoring task by pressing a response button if they heard the target. Response latencies were measured (as in Experiment 2) from the onset of the target vowel.

\section{Results}

Unsurprisingly, performance in this experiment was slower, and there were more errors, than in Experiment 2 (see Table 4). Six participants showed error rates above $25 \%$, and their data were excluded from further analysis. One item in the enchainment condition was erroneously presented with full sentential context and was therefore excluded as well.

Despite the removal of the initial and final portions of the auditory stimuli, the liaison condition showed a 48msec advantage over the syllable-aligned condition and a 57-msec advantage over the enchainment condition. ANOVAs on the response time data revealed an effect of target context that was significant by participants, but not by items $\left[F_{1}(2,72)=6.3, p<.01 ; F_{2}(2,52)=2.2, p=.12\right]$. In the error analysis, the effect of target context was again significant by participants, but not by items $\left[F_{1}(2,72)=\right.$ $3.7, p<.05 ; F_{2}(2,52)=2.1, p=.13$ ], with the liaison condition showing the fewest errors, as well as the fastest responses.

\section{Discussion}

Experiment 3 was intended to provide preliminary evidence for the source of the facilitation effects for resyllabified speech in word monitoring in Experiment 2. We suggested four possible causes of these effects, which varied in terms of the type of information required. Of these four, two options now appear unlikely. If the effect in Experiment 2 was due to a relative difficulty in picking out target vowels from vowel-vowel transitions, as opposed to consonant-vowel transitions, the pattern of response times should have remained unchanged. Although there was reasonable evidence that the liaison advantage over syllable aligned remained in Experiment 3 (a 48-msec, or 6\%, reduction in response speed, as compared with $44 \mathrm{msec}$, or $9 \%$, in Experiment 2), the difference between the enchainment and the aligned conditions vanished entirely ( $-9 \mathrm{msec}$, or $-1 \%$, as compared with $36 \mathrm{msec}$, or $7 \%$, in Experiment 2).

The plausibility that syntactic differences between the liaison condition and the other two conditions influenced response speed in Experiment 2 is also further weakened by the results of Experiment 3, although in this case, it cannot be ruled out entirely. The excision of the beginnings and ends of the phrases eliminated the availability of syntactic information, yet there remained a marginal effect of context type, which appeared to be due largely to fast responses in the liaison condition. Nonetheless, this effect was only marginal, and there remains the slight possibility that syntactic differences in the composition of the stimulus phrases had consequences for the prosody of the phrases and that these prosodic differences remained in the auditory stimuli for Experiment 3.

The results of Experiment 3 undermine the two relatively uninteresting explanations of the resyllabification advantage shown in Experiment 2. However, we still cannot fully determine the source of the facilitatory effects of resyllabification on monitoring for vowel-initial words. We argued that recognition of the word preceding the resyllabified consonant should lead to speeded recognition for enchainment, but not for liaison. Experiment 3 supported this explanation, because the preceding words were made unrecognizable by excision of their onsets and this manipulation eliminated the enchainment advantage over syllable alignment. Equally, the residual (statistically weaker) advantage that appeared to remain for the liaison condition could be explained by the presence of acoustic markings of liaison that were available in both Experiments 2 and 3 to facilitate responses. Therefore, there may be two sources of information working, with stronger effects of lexical knowledge in the case of enchainment and stronger acoustic cues in the case of liaison. However, an alternative explanation is that our manipulation of the spo- 
ken stimuli has simply made durational (and possibly other) acoustic cues harder to identify, which has resulted in an across-the-board weakening of the resyllabification advantage. Evidence from further experiments will be required if these suggestive accounts are to be properly validated.

\section{GENERAL DISCUSSION}

In this research, we addressed an important test case for the syllable as a unit in the perception of romance languages, such as French. In all four experiments, we found no evidence for a processing cost of misalignment between word and syllable boundaries caused by liaison or enchainment. The two priming subexperiments showed equally strong lexical activation for syllable-aligned and syllable-misaligned words during the perception of those words. Using word monitoring, we found a clear advantage for the misaligned conditions in the recognition of the next word. Finally, using sequence monitoring with the beginnings and ends of the spoken stimuli removed, we found no cost for enchainment and weaker evidence for a benefit in the case of liaison. Therefore, none of the experiments showed any support for the idea that resyllabification impairs or delays the recognition of the following word, and the only effects we found were suggestive of a benefit for resyllabification. Here, we will discuss the implications of these findings for theories for models of segmentation and word recognition. First, however, we will speculate on the possible causes of the facilitative effects found for syllable-word boundary alignment with word monitoring in Experiment 2 and, more weakly, with sequence monitoring in Experiment 3.

It is currently unclear exactly what information sources underpin the benefits found, but they are likely to include some combination of lexical and acoustic cues to the presence of resyllabified consonants, allowing the perceptual system to anticipate a valid phonological context for the resyllabification. Our stimuli, like others, show a reduction in consonant duration associated with resyllabification, and there may be other, more subtle markings of resyllabified consonants. Of course, simply identifying an acoustic difference between resyllabified and normal syllable-initial consonants tells us nothing about whether this difference is exploited by the perceptual system. But given the striking sensitivity of the perceptual system to subphonemic information in similar domains (e.g., Davis, Marslen-Wilson, \& Gaskell, 2002; Hawkins \& Nguyen, in press), it would be surprising if this information was ignored. If listeners do exploit these durational cues, a word boundary can be predicted from the observation of a shortened consonant, and a suitable following segment (i.e., a liquid or a vowel) can also be predicted. Both of these factors would assist in the recognition of a following vowelinitial word. The situation here is similar to the effects of between-word place assimilation in English and Dutch
(Gaskell \& Marslen-Wilson, 1998; Gow, 2001; Quené et al., 1998), in which the observation of variation (e.g., lean bacon becomes leam bacon) triggers the expectation of the context that caused that change, and vice versa. Such constraint-based inference is easily learned by a statistical learning mechanism, such as a simple recurrent network (Gaskell, Hare, \& Marslen-Wilson, 1995).

Gaskell and Marslen-Wilson (1998) advanced two potential mechanisms for the contextual use of phonological variation. A prelexical mechanism relies only on observation of the variation to predict the viable context. A lexical mechanism relies on identification of the word carrying the variant. Gaskell and Marslen-Wilson found that when carrier sequences were changed into nonwords (e.g., geam bacon instead of leam bacon), the contextual effect was weakened but not eliminated. They argued that both lexical and prelexical information sources were combined in order to resolve the ambiguity caused by the phonological change.

A similar issue arises in the case of resyllabification. If durational changes are sufficiently obvious, they can be used to predict the appropriate context without recourse to lexical knowledge. This fits in with the weak liaison advantage in Experiment 3, in which lexical information was largely absent. A number of lines of evidence, however, suggest that acoustic influences, on their own, cannot underlie the full pattern of effects found here. First, the acoustic analyses themselves suggest that consonant duration alone will not be an infallible indicator of resyllabification. Although there is a clear difference between the mean durations of resyllabified and normal syllable-initial consonants, the distributions are very much overlapping. In our stimuli, $17 \%$ of the liaison consonants had a duration as long as or longer than the mean of the word-initial consonants, and $83 \%$ had a longer duration than the shortest initial consonant we examined. Unless there are other, more discriminating cues or combinations of cues, this suggests that acoustic information about consonant duration can only be used probabilistically.

Furthermore, although the effects of resyllabification remained for the liaison condition in Experiment 3, they were eliminated for the enchainment condition. The predictive information in the resyllabified enchainment consonants was not sufficient to generate strong facilitation of responses to the target sequences when lexical access failed. Although the source of the facilitation effects found in these experiments is not fully clear, our best estimate at present is that lexical and acoustic factors are both influential, with lexical influences critical in the enchainment advantage found in Experiment 2.

Finally, Dejean de la Bâtie and Bradley's (1995) results can be interpreted as a tendency to compensate for liaison even in the absence of any acoustic cues to liaison. As we mentioned, their study showed that responses were slower to potential liaison sequences (e.g., excellent tableau) than they were to unambiguous sequences (e.g., vrai tableau). This can be explained as a tendency to treat the initial/t/ 
of tableau as a liaison consonant, increasing activation of "a"-initial words, despite the absence of any acoustic cues to liaison.

It is worth noting that although the two studies most closely related to the present research (Dejean de la Bâtie \& Bradley, 1995; Vroomen \& de Gelder, 1999) show inhibitory effects of resyllabification processes, their findings are not incompatible with ours. As we have mentioned, Dejean de la Bâtie and Bradley's results can be interpreted in terms of the observation of a potential liaison's strengthening the hypothesis that there is a vowel-initial word following the consonant in question. The word-monitoring results here (and to a lesser extent, the sequence-monitoring results) suggest that the same process is operating in the case of actual resyllabifications. The Vroomen and de Gelder (1999) study showed inhibitory effects on the perception of the resyllabified consonant itself, whereas our study examined the effects of resyllabification processes on the following context. The picture from the combined results suggests a certain symmetry in the informational content of resyllabification. The process results in increased ambiguity over the status of the consonant itself, but once that ambiguity has been resolved (possibly by combining lexical knowledge with acoustic information), there is a consequent informational advantage in the predictability of the following context that licenses the resyllabification. A similar picture has emerged in the perception of place assimilation and the anticipation of its phonological context (Gaskell \& Marslen-Wilson, 1998; Gow, 2001).

In summary, although further research is necessary to clarify the conditions under which resyllabification in French can facilitate speech processing, converging evidence from a number of sources suggests that the predictive use of resyllabification cues relies on some combination of two types of information-acoustic correlates of resyllabification and lexical information about word forms and their boundaries. Although there is some evidence that each can operate in the absence of the other, it may be that both are used in the normal course of events to assist in the segmentation and recognition of words. This gives a boost to the immediate activation of words that provide a viable context for resyllabification processes, as demonstrated in Experiment 2. However, given the equally strong priming in all the test conditions in Experiment 1, it is important to bear in mind that this initial advantage is transient. The monitoring experiments primarily measured the speed of recognition of the initial segments of the target words. The results of Experiment 1B showed that by halfway through the next word, the advantage for the resyllabification conditions had disappeared. It seems that the normal course of lexical activation and competition is sufficient to activate the correct lexical items for the stimuli in the syllable-aligned condition of Experiment 1 . This is perhaps not surprising, given that in all conditions, there is abundant information available in the speech signal that can be used to identify the initial seg- ments of the vowel-initial segments. In all cases, these segments are identified, and the correct word is recognized. The only difference is that the resyllabified consonant seems to provide a small and transient advantage in speed of identification of the following vowel.

\section{Theories of Segmentation and Word Recognition}

We began this article by listing possible theoretical reasons that resyllabification may cause problems for understanding the following word. Given that we have experimental results demonstrating that, at worst, liaison and enchainment do not interfere with recognition and, at best, these processes facilitate recognition, we must now reevaluate the theories in this new light.

The PWC (Norris et al., 1997) states that a potential segmentation of the speech stream is disfavored if it leaves a consonant or consonant sequence stranded between a known word boundary and a hypothesized boundary. In the case of romance languages, known or likely word boundaries would include all syllable boundaries. Norris et al. noted that this constraint could cause problems for the perception of liaison in French and suggested that acoustic and lexical information could be used to identify liaison consonants and "switch off" this constraint. The present results are not at odds with the PWC, because liaison and enchainment are seen as exceptional cases for which the constraint does not apply. The word-monitoring data, however, do refine the role of resyllabification in the PWC. They suggest that when resyllabified consonants are identified by the system, the response is more than simply a blocking of the standard strategy. The information appears to be used positively, to predict the context that licenses the phonological process and to boost (very transiently) the activation of words that contain the relevant context. Given that the perceptual system is required to identify these consonants in order to inhibit erroneous segmentations of the speech stream, it seems quite natural that the information should also be used beneficially, to hone predictions about the upcoming speech.

The second theory that might predict inhibitory effects of resyllabification is the syllable hypothesis (Mehler et al., 1981). Two different strands of this theory have emerged, one relating to the basic units of representation in lexical access and a second relating to word segmentation. Both these strands would, on the face of it, predict that resyllabification should interfere with the recognition of the following word. The access strand of the syllable hypothesis would require complex mappings between syllable units and lexical entries in order to allow the correct word to be recognized using only syllabic units (e.g., for an enchainment sequence, the syllable containing the resyllabified word would need to be part-mapped onto two separate words). Alternatively, the access version of the syllable hypothesis could allow for smaller units of representation to dominate in cases like this (cf. Sebastian-Gallès et al., 1992), but even then one would expect the reliance on an 
alternative representation to have a cost in terms of processing time comparable to the syllable misalignment cost in Mehler et al.'s original research.

It may be more advantageous to turn instead to the segmentation version of the syllable hypothesis. Given a lack of preferential evidence for the access version of the syllable hypothesis, plus their own evidence favoring the segmentation version, Content, Dumay, and Frauenfelder (2000; see also Content, Meunier, Kearns, \& Frauenfelder, 2001) argued for the syllable onset segmentation hypothesis (SOSH) in French. SOSH assumes that lexical access relies on relatively small units of access, such as features or phonemes, but that the syllable onset is a privileged alignment point for a lexical search. Their model takes advantage of the strong correlation between syllable and word onsets in French. A simple application of this strategy would again lead to the prediction that resyllabification causes problems for recognition, and indeed this prediction has been confirmed in the case of the resyllabification before consonants such as / $\mathrm{r} /$ and /l/ (Dumay et al., 1999). However, as in the PWC model, if resyllabified consonants can be identified as such, either through the application of lexical knowledge or the recognition of acoustic markings, it is possible that a more flexible version of SOSH could accommodate our results.

In summary, the lack of a resyllabification cost in the perception of vowel-initial words and the suggestion of some transient advantages associated with enchainment and liaison demand a flexible view of the role of the syllable in the perception of French in particular and in speech perception in general. Our results appear incompatible with the idea that syllable is the basic unit of perception for French listeners. Instead, they suggest that syllable onset should be thought of as one of several cues to likely word onsets. For vowel-initial words, it appears that we can use other information (e.g., lexical, acoustic, and phonological) to compensate for resyllabification and its consequent misalignment of syllable and word boundaries. It may even be the case that these cues can operate in the listener's favor and briefly facilitate the recognition of words misaligned in this way.

\section{REFERENCES}

Bradley, D. C., Sánchez-Casas, R. M., \& García-Albea, J. E. (1993). The status of the syllable in the perception of Spanish and English. Language \& Cognitive Processes, 8, 197-233.

BRENT, M. R. (1999). Speech segmentation and word discovery: A computational perspective. Trends in Cognitive Sciences, 3, 294-301.

Cairns, P., Shillcock, R., Chater, N., \& Levy, J. (1997). Bootstrapping word boundaries: A bottom-up corpus based approach to speech segmentation. Cognitive Psychology, 33, 111-153.

Content, A., Dumay, N., \& Frauenfelder, U. H. (2000). The role of syllable structure in lexical segmentation: Helping listeners avoid mondegreens. In A. Cutler, J. M. McQueen, \& R. Zonderon (Eds.), Proceedings of the SWAP conference (pp. 39-42). Nijmegen: Max Planck Institute for Psycholinguistics.

Content, A., Meunier, C., Kearns, R. K., \& Frauenfelder, U. H. (2001). Sequence detection in pseudowords in French: Where is the syllable effect? Language \& Cognitive Processes, 16, 609-636.

Cutler, A., \& Butterfield, S. (1992). Rhythmic cues to speech seg- mentation: Evidence from juncture misperception. Journal of Memory \& Language, 31, 218-236.

Cutler, A., \& CARTER, D. M. (1987). The predominance of strong initial syllables in the English vocabulary. Computer Speech \& Language, 2, 133-142.

Cutler, A., Demuth, K., \& McQueen, J. M. (2002). Universality versus language-specificity in listening to running speech. Psychological Science, 13, 258-262.

Cutler, A., Mehler, J., Norris, D., \& Segui, J. (1986). The syllable's differing role in segmentation of French and English. Journal of Memory \& Language, 25, 385-400.

Cutler, A., \& Norris, D. (1988). The role of strong syllables in segmentation for lexical access. Journal of Experimental Psychology: Human Perception \& Performance, 14, 113-121.

Davis, M. H., Marslen-Wilson, W. D., \& Gaskell, M. G. (2002). Leading up the lexical garden path: Segmentation and ambiguity in spoken word recognition. Journal of Experimental Psychology: Human Perception \& Performance, 28, 218-244.

Dejean de la BÂtie, B., \& Bradley, D. C. (1995). Resolving word boundaries in spoken French: Native and nonnative strategies. Applied Psycholinguistics, 16, 59-81.

Dumay, N., Content, A., \& Frauenfelder, U. H. (1999). Acousticphonetic cues to word boundary location: Evidence from word spotting. In Proceedings of ICPhS'99 (pp. 281-284). Berkeley, CA: University of California, Linguistics Department.

Dumay, N., Frauenfelder, U. H., \& Content, A. (2002). The role of the syllable in lexical segmentation in French: Word-spotting data. Brain \& Language, 81, 144-161.

Foss, D. J. (1969). Decision processes during sentence comprehension: Effects of lexical item difficulty and position upon decision times. Journal of Verbal Learning \& Verbal Behavior, 8, 457-462.

Frauenfelder, U. H., \& Content, A. (1999). The role of the syllable in spoken word recognition: Access or segmentation. In Actes des 2ièmes Journées d'Études Linguistiques (pp. 1-8). Nantes, France: Université de Nantes, Équipe AAI.

Gaskell, M. G., Hare, M., \& Marslen-Wilson, W. D. (1995). A connectionist model of phonologicalrepresentation in speech perception. Cognitive Science, 19, 407-439.

Gaskell, M. G., \& Marslen-Wilson, W. D. (1998). Mechanisms of phonological inference in speech perception. Journal of Experimental Psychology: Human Perception \& Performance, 24, 380396.

Gow, D. W. (2001). Assimilation and anticipation in continuous spoken word recognition. Journal of Memory \& Language, 45, 133-159.

Grosjean, F. (1996). Gating. Language \& Cognitive Processes, 11, $597-$ 604.

HAwKIns, S., \& NGUYen, N. (in press). Effects on word recognition of syllable-onset cues to syllable-coda voicing. In J. K. Local, R. A. Ogden, \& R. A. M. Temple (Eds.), Papers in Laboratory PhonologyVI. Cambridge: Cambridge University Press.

Imbs, P. (1971). Trésor de la langue Française: Dictionnaire des fréquences [Resource of the French language: Dictionary of frequencies]. Paris: Klincksieck.

Kilborn, K., \& Moss, H. (1996). Word monitoring. Language \& Cognitive Processes, 11, 689-694.

McQueen, J. M. (1998). Segmentation of continuous speech using phonotactics. Journal of Memory \& Language, 39, 21-46.

Mehler, J., Dommergues, J. Y., Frauenfelder, U., \& Segui, J. (1981). The syllable's role in speech segmentation. Journal of Verbal Learning \& Verbal Behavior, 20, 298-305.

Morais, J., Content, A., Cary, L., Mehler, J., \& Segui, J. (1989). Syllabic segmentation and literacy. Language \& Cognitive Processes, 4 , 57-67.

Norris, D., McQueen, J. M., Cutler, A., \& Butterfield, S. (1997). The possible-word constraint in the segmentation of continuous speech. Cognitive Psychology, 34, 191-243.

Pollatsek, A., \& Well, A. D. (1995). On the use of counterbalanced designs in cognitive research: A suggestion for a better and more powerful analysis. Journal of Experimental Psychology: Learning, Memory, \& Cognition, 21, 785-794. 
Quené, H., van Rossum, M., \& VAn WiJck, M. (1998, December). Assimilation and anticipation in word perception. Paper presented at the Fifth International Conference on Spoken Language Processing, Sydney, Australia.

Raaijmakers, J. G. W., Schrijnemakers, J. M. C., \& Gremmen, F. (1999). How to deal with "the language-as-fixed-effect fallacy": Common misconceptions and alternative solutions. Journal of Memory \& Language, 41, 416-426.

Saffran, J. R., Aslin, R. N., \& Newport, E. L. (1996). Statistical learning by 8-month-old infants. Science, 274, 1926-1928.

Sebastian-Gallès, N., Dupoux, E., Segui, J., \& Mehler, J. (1992). Contrasting syllabic effects in Catalan and Spanish. Journal of Memory \& Language, $\mathbf{3 1}, 18-32$.

Spinelli, E., McQueen, J. M., \& Cutler, A. (in press). Processing resyllabified words in French. Journal of Memory \& Language.

Vroomen, J., \& DE Gelder, B. (1997). Activation of embedded words in spoken word recognition. Journal of Experimental Psychology: Human Perception \& Performance, 23, 710-720.
VRoomen, J., \& DE Gelder, B. (1999). Lexical access of resyllabified words: Evidence from phoneme monitoring. Memory \& Cognition, 27, 413-421

Yersin-Besson, C., \& Grosjean, F. (1996). L'effet de l'enchainement sur la reconnaissance des mots dans la parole continue [The effect of enchainment on the recognition of words in continuous speech]. L'année Psychologique, 96, 9-30.

\section{NOTES}

1. Content, Meunier, Kearns, and Frauenfelder (2001) question the generality of Mehler et al.'s (1981) original result, arguing that identification of syllable boundaries, rather than syllable units, is critical in the perception of spoken French. We will discuss their alternative model in the General Discussion section.

2. Cairns, Shillcock, Chater, and Levy (1997) calculated that a segmentation strategy based on strong syllables should aid recognition of $50 \%$ of all English words, with a false alarm rate of only $5 \%$.

\section{APPENDIX A}

Auditory Stimuli for Experiments 1-3

\begin{tabular}{|c|c|c|c|}
\hline Liaison & Enchainment & Syllable Aligned & Control \\
\hline un mauvais original & un malaise original & un oiseau original & un fameux industriel \\
\hline un singulier optimiste & un univers optimiste & un infini optimiste & un adversaire exécrable \\
\hline un léger accident & un sévère accident & un mini accident & un concert officiel \\
\hline un grand impulsif & un geste impulsif & un fou impulsif & un doute incessant \\
\hline un parfait humaniste & un poète humaniste & un garçon humaniste & un puissant explosif \\
\hline un petit imprévu & un contact imprévu & un morceau imprévu & un affreux oreiller \\
\hline un premier exemplaire & un devoir exemplaire & un patron exemplaire & un regard expressif \\
\hline un fervent idéaliste & un concept idéaliste & un neveu idéaliste & un notaire extravagant \\
\hline un généreux italien & un virtuose italien & un chapeau italien & un mystérieux organisme \\
\hline un gracieux interprète & un grandiose interprète & un joli interprète & un discours ambitieux \\
\hline un faux autrichien & un vase autrichien & un vrai autrichien & un bref entretien \\
\hline un précieux idéal & un gymnase idéal & un tableau idéal & un curieux animal \\
\hline un second empire & un modeste empire & un salon empire & un réel effort \\
\hline un glorieux anniversaire & un morose anniversaire & un repas anniversaire & un sérieux attachement \\
\hline un maudit insolent & un artiste insolent & un baron insolent & un cruel empereur \\
\hline un régulier entraînement & un nécessaire entraînement & un quasi entraînement & un délicieux apéritif \\
\hline un éminent intellectuel & un anarchiste intellectuel & un écrivain intellectuel & un dangereux enseignemer \\
\hline un familier habitue & un militaire habitue & un cerveau habitue & un étonnant appétit \\
\hline un long hiver & un seul hiver & un fichu hiver & un triste avenir \\
\hline un joyeux infirme & un obèse infirme & un client infirme & un flagrant attrait \\
\hline un dernier objectif & un savoir objectif & un récit objectif & un fâcheux incident \\
\hline un brillant employé & un chimiste employé & un rigolo employé & un heureux évènement \\
\hline un séduisant argentin & un diplomate argentin & un vigneron argentin & un passionnantépisode \\
\hline un excellent amateur & un journaliste amateur & un musicien amateur & un précédent omnibus \\
\hline un galant homme & un honnête homme & un demi homme & un stupide ordre \\
\hline un violent orgueilleux & un adulte orgueilleux & un gascon orgueilleux & un stagiaire efficace \\
\hline un profond ennui & un funeste ennui & un méga ennui & un urgent appel \\
\hline un grossier apprenti & un vulgaire apprenti & un agent apprenti & un liquide incolore \\
\hline un méchant ennemi & un pilote ennemi & un avion ennemi & un arbuste inutile \\
\hline un gros interdit & un gaz, interdit & un vin interdit & un cher adhérent \\
\hline
\end{tabular}

Note-The control condition was used only in Experiment 1. Italicized sections mark the excised sequences used in Experiment 3 . 